$$
\text { بسم الله الرحمن الرحيم }
$$

\title{
كلمة التمريز
}

\section{Editorial Words}

\section{Kata Pengantar}

الحمد لله الذي علم بالقلم، وعلم الإنسان ما لم يعلم، والصلاة والسلام على رسوله المصطفى الذي أنزل عليه القرآن بلسان عربي مبين، وعلى آله وصحبه الغر الميامين.

نقف في هذا العدد الثاني من بحلة الدراسات اللغوية والأدبية على مفترق طرق يذهب بنا إلى آفاق واسعة للبحث في اللغة العربية وآداها؛ إذ إن من طبيعة المنشورات العلمية اللغوية الموثوقة أن تتناول قضايا حيوية وملحة في اللغة والأدب تتعلق بالقراءة والمفكرين والباحثين من جانب الحياة الثقافية والاجتماعية والفكرية، وتتطرق إلى الدراسات اللغوية والأدبية في بحال التعليم وتحليل النص والتأصيل للدراسات اللغوية والأدبية.

هذا العدد هو ثمرة لجهود قامت بها لجنة التحرير عبر مراجعة المقالات، والعمل على اختيار الأنسب منها، بعد تحكيمها من قبل محكمين ذوي خبرة عالية وتخصصات دقيقة، لتحقق هذه المقالات أهداف المجلة التي ترنو إلى تأسيس دراسات لغوية وأدبية تربط بين التراث والمعاصرة، وتملك زمام المبادرة في إبراز هذه الدراسات بمنهجية علمية صارمة، تتضمن موضوعات حيوية فيها بتديد ينهض بالأمة الإسلامية فكريا وثقافيا.

تضمنت المقالات اللغوية موضوعات حيوية تتعلق بالربط بين التراث والمعاصرة في بحال فهم النص عبر مقاربة لسانية تداولية التقى فيها علماء أصول الدين مع نظرية معاصرة للعالم الغربي (جرايس) في تحقيق إبلاغية الرسالة اللغوية؛ وفي بحال التعليم خلصت دراسة الاتحاهات نخو القراءة باللغة العربية للناطقين بغيرها إلى أن القلق والمتعة والقيمة والإدراك من العوامل المهمة التي تعكس اتبحات الطلبة غير الناطقين بالعربية نحو دراستها وفهمها؛ أما 
مشكلات دراسة العربية في أقسام اللغة العربية وآداها في الجامعات العربية، فقد تناولتها دراسة ديداكتيك أو تعليمية اللغة ومشاريع الإصلاح، وأشارت إلى سوء التخطيط في المنظومة التربوية العربية في توجيه طلبة الدراسات الجامعية الأولى (البكالوريوس)؛ لعدم رغبة كثير من الدارسين في دراسة اللغة العبية وآداها، وأن سبب اختيار هذا التخصص هو سهولة القبول في أقسام اللغة العربية وآدابها للمعدلات المتدنية، وعدم وجود بديل آخر للدراسة في الجامعة، وقد كان لذلك آثار سلبية في ضعف المتخصصين في اللغة العببية وآدابها أداء وممارسة وكفاية لغوية؛ وأما موضوع الآثار والنقوش العربية القديمة فقد أثنارت دراسة لهجة ثمود بين الواقع والوهم قضية صحة هذه الآثار، وأثها تقوم على الظن والتخمين والوهم؛ لأن القرآن الكريع الذي لم يدخله التحريف عبر الزمان أشار إلى أن قوم ثمود لم يبق لهم أثر قط بعدما أصاهم من تدمير؛ وفي موضوع إعراب أسماء الله تعالى وصفاته فقد هدفت الدراسة هذه إلى وجوب تعظيم الله عز وجل، ومن لوازم تعظيمه التعظيم والتوقير والأدب مع أسمائه وصفاته في الخطاب والإعراب، وألا تعامل كغيرها من الأسماء في الخطاب أو الإعراب، وهذا ما تتناوله الدراسة بالتحقيق.

أما الدرسات الأدبية فتبدأ بدراسة صورة الآخر في التراث، وتمدف إلى فهم الذات والآخر، وخير مثال مؤلفات الجاحظ الذي انفتح على الآخر بسبب ثقافته الإسلامية؛ حيث رسخ رؤية متوازنة للآخر تقصي التعصب جانبا، وتؤسس بلمتمع التسامح؛ والدراسة الثانية تتعلق بالقيم الأخلاقية عند الشعراء المسلمين بأفريقيا عبر دعوقمم إلى التحلي بالقيم الخلقية عن طريق شعر الزهد المدمج بالحكمة عبر العظة والعبرة والنصائح والعظات، لما في ذلك من أثر في الجمتمعات الإسلامية التي الحدرت أخلاقيا؛ وفي دراسة آداب العالم الإسلامي برزت دراسة إسهامات الروائي الباكستاني نسيم حجازي في روايته التي تضاهي الأعمال الأدبية العالمية؛ لأغا تصور مظالم الهندوس والسيخ للمسلمين بعد قيام دولة باكستان عام 9 9 (1م، وصورت الواقع المرير في قالب فني جميل مؤثر؛ وفي تحليل النصوص الشعرية القديمة عبر دراسة أسلوب الترميز لقصيدة عمرو بن الأهتم المنقري، أشارت الدراسة إلى حالة الاغتراب ورفضه في بحتمع بدأت فيه منظومة الفضائل تهن وتتضاءل، وسلطت الضوء على الألفاظ ذات الدلالة المباشرة وغير المباشرة على هذه المعاني؛ وأخيرا دراسة شعر الحكمة لدى الشعراء النصارى في العصر الأموي وما تتضمنه من مضامين إسلامية عبر دراسة شعراء سبعة بوصفهم نموذجا للدراسة؛ وختم هذا العدد في موضوع نقد وآراء بمراجعة 
كتاب (مصادر القواعد النحوية في ميزان الشرع والعقل)، وقد تناولت المراجعة نقدا لبعض الآراء الواردة في الكتاب، مع بيان الدليل العلمي، وبينت إيبابيات الكتاب في مقاربة نقدية فعالة.

وأخيرا تتقدم هيئة التحرير بجزيل الشكر والتقدير لكل الإسهامات التي أدت إلى إعداد هذا العدد بشكله الأخير، داعين الله تعالى أن يوفقنا جميعا نخو خدمة لغة القرآن الكريع دراسة وبكثا وتطويرا.

هيئة التحرير 